Fanum

Sociológico

\section{Forum Sociológico}

Série II

$20 \mid 2010$

A pobreza, pluralidade de olhares e de intervenções

\title{
Acesso universal a qualificações certificadas: para a ruptura da relação entre insucesso escolar e desigualdades sociais
}

Luís Capucha

\section{(2) OpenEdition \\ Journals}

Edição electrónica

URL: https://journals.openedition.org/sociologico/174

DOI: 10.4000/sociologico.174

ISSN: 2182-7427

Editora

CICS.NOVA - Centro Interdisciplinar de Ciências Sociais da Universidade Nova de Lisboa

\section{Edição impressa}

Data de publição: 1 junho 2010

Paginação: 47-55

ISSN: 0872-8380

\section{Refêrencia eletrónica}

Luís Capucha, «Acesso universal a qualificações certificadas: para a ruptura da relação entre insucesso escolar e desigualdades sociais », Forum Sociológico [Online], 20 | 2010, posto online no dia 05 setembro 2012, consultado o 30 março 2022. URL: http://journals.openedition.org/sociologico/174 ; DOI: https://doi.org/10.4000/sociologico.174

Este documento foi criado de forma automática no dia 30 março 2022

(c) CICS.NOVA 


\title{
Acesso universal a qualificações certificadas: para a ruptura da relação entre insucesso escolar e desigualdades sociais
}

\author{
Luís Capucha
}

\section{Pobreza, qualificações e insucesso escolar}

1 Todos os estudos conhecidos sobre a génese e a reprodução da pobreza coincidem num aspecto: as qualificações são um factor incontornável. Podemos percorrer quase toda a literatura sobre o tema que encontraremos sempre referências, mais ou menos explícitas, a essa relação.

2 A associação entre os dois fenómenos está evidenciada na Tabela 1. A probabilidade de se ser pobre é mais de seis vezes superior entre quem possui um nível de escolaridade equivalente ao ISCED 0,1 e 2 do que entre quem possui o correspondente ao ISCED 5 e 6 . Neste caso, a probabilidade de se ser pobre é quase três vezes menor do que para quem possui qualificações intermédias (ISCED 3-4), enquanto os menos qualificados apresentam um risco mais do que duplo destes últimos.

3 O Censos de 2001, a última informação exacta que possuímos a este respeito, mostra também que, quando a taxa de pobreza era de $21 \%$, a distribuição do risco entre os níveis de qualificação era fortemente penalizadora para os menos escolarizados: apenas $1 \%$ para o ensino superior, $8 \%$ para o secundário e $23 \%$ para os que tinham menos do que o secundário.

4 As qualificações fazem, portanto, a diferença. Face a esta evidência, abrem-se duas questões: como é que a posse de capital escolar se transforma em recurso preventivo da pobreza? Que efeito tem o facto de se ser pobre sobre a aquisição do capital escolar? 
Tabela 1 Taxa de risco de pobreza após as transferências sociais, por nível de escolaridade e sexo (2007)

\begin{tabular}{|l|l|l|l|l|l|l|l|l|l|}
\hline Escolaridade & \multicolumn{3}{|c|}{ ISCED 0-2 } & \multicolumn{3}{|c|}{ ISCED 3-4 } & \multicolumn{3}{|c|}{ ISCED 5-6 } \\
\hline Sexo & T & H & M & T & H & M & T & H & M \\
\hline Portugal & 19 & 18 & 21 & 8 & 7 & 10 & 3 & 2 & 3 \\
\hline UE27 & 24 & 23 & 24 & 13 & 12 & 14 & 6 & 6 & 7 \\
\hline
\end{tabular}

FONTE: Eurostat, Statistics on Income and Living Conditions (SILC), 2008. ${ }^{1}$

5 As duas questões estão interligadas e fazem parte daquilo a que comummente se chama o "círculo vicioso da pobreza". Os pobres têm mais dificuldades em obter vantagens da escola e, em função disso, vêem ser-lhes vedado um recurso essencial para deixar a condição que os caracteriza.

6 Ao longo do presente artigo deixaremos de lado a primeira questão para nos concentrarmos na segunda.

7 A escola pública tem como desígnio formal a igualdade de oportunidades (Rodrigues, 2010; Terrail, 2002). Ela é, na ordem institucional moderna, a instituição à qual compete promover as condições necessárias à mobilidade social em função do esforço e do mérito, enquanto, ao mesmo tempo, deveria fornecer a todos o mínimo de "instrução pública" elementar com vista à participação social. Como escreveu Bourdieu já há mais de duas décadas, “... o Estado deve assegurar a todos o mínimo cultural comum, condição do exercício duma actividade profissional bem-sucedida e da manutenção do mínimo de comunicação indispensável ao exercício esclarecido dos direitos do homem e do cidadão" (1987: 110). Consegue a escola cumprir essa missão? Ajuda ou não a combater a desigualdade e, logo, a promover a justiça social?

Ora, como mostra a investigação sociológica, os alunos dos meios mais desfavorecidos são hoje levados à escola, que se massificou. Mas aos progressos registados na escolarização (proporção de crianças e jovens que frequentam a escola) não correspondem a progressos equivalentes na escolaridade (níveis de certificação escolar).

Tabela 2 Taxa de Escolarização, segundo o Ano Lectivo, por Idade (\%) ${ }^{2}$

\begin{tabular}{|l|l|l|l|l|l|l|l|l|}
\hline & $\mathbf{2 0 0 0 / 0 1}$ & $\mathbf{2 0 0 1 / 0 2}$ & $\mathbf{2 0 0 2 / 0 3}$ & $\mathbf{2 0 0 3 / 0 4}$ & $\mathbf{2 0 0 4 / 0 5}$ & $\mathbf{2 0 0 5 / 0 6}$ & $\mathbf{2 0 0 6 / 0 7}$ & $\mathbf{2 0 0 7 / 0 8}$ \\
\hline $\mathbf{1 1}$ anos & 100,0 & 100,0 & 100,0 & 100,0 & 100,0 & 100,0 & 100,0 & 100,0 \\
\hline $\mathbf{1 2}$ anos & 100,0 & 100,0 & 100,0 & 100,0 & 100,0 & 100,0 & 100,0 & 100,0 \\
\hline $\mathbf{1 3}$ anos & 100,0 & 100,0 & 100,0 & 100,0 & 100,0 & 100,0 & 100,0 & 100,0 \\
\hline $\mathbf{1 4}$ anos & 100,0 & 100,0 & 100,0 & 100,0 & 100,0 & 100,0 & 100,0 & 100,0 \\
\hline $\mathbf{1 5}$ anos & 93,0 & 92,9 & 95,4 & 92,3 & 91,7 & 90,8 & 99,9 & 100,0 \\
\hline
\end{tabular}




\begin{tabular}{|l|l|l|l|l|l|l|l|l|}
\hline $\mathbf{1 6}$ anos & 87,4 & 83,2 & 83,2 & 80,3 & 81,0 & 81,7 & 91,1 & 94,3 \\
\hline $\mathbf{1 7}$ anos & 75,4 & 74,2 & 71,8 & 74,8 & 76,4 & 72,8 & 80,5 & 82,9 \\
\hline $\mathbf{1 8}$ anos & 62,3 & 61,7 & 63,5 & 65,7 & 66,9 & 67,4 & 65,5 & 65,4 \\
\hline
\end{tabular}

Fonte: GEPE.

9 Na verdade, em Portugal, desde o ano lectivo de 2007/2008 a taxa de escolarização aos 15 anos atingiu os $100 \%$. É provável que estejamos, já hoje, com a mesma taxa aos 16 anos, e aos 17 os valores eram naquela altura perto de $95 \%$. Com o acréscimo de 40000 alunos no secundário em 2009/2010 relativamente ao ano de 2005/2006, estaremos ainda mais perto da escolaridade universal até aos 17 anos. Mas as retenções fazem que nem sempre o estar na escola signifique o sair dela com a escolaridade considerada mínima para a vida e o trabalho na sociedade da informação.

10 A taxa de frequência da escola tem vindo a aumentar de forma lenta mas sustentada, pelo menos para os menores de 17 anos. Isso tem feito transferir a evidência do insucesso para níveis superiores do sistema escolar. Assim, se em meados dos anos $80 \mathrm{e}$ durante a primeira metade dos 90 o foco estava essencialmente no primeiro ciclo (Benavente, 1990; Benavente et al., 1987) e, depois, na escolaridade básica de 9 anos, agora tem vindo a transferir-se para o nível secundário.

11 O insucesso escolar tende a ser socialmente orientado, precoce e cumulativo (Benavente, 1990; Benavente et al., 1994). Isto é, (i) a probabilidade de uma criança ou um jovem conhecer o insucesso escolar é inversamente proporcional aos recursos da sua família; (ii) a forma mais simples do insucesso, a retenção num determinado ano, tende a ser precoce; (iii) as crianças e jovens atingidos uma vez tendem a sê-lo noutras ocasiões, até abandonarem a escola sem atingirem os patamares mínimos de escolaridade. Por outro lado, a probabilidade de prosseguir estudos de nível superior é directamente proporcional aos recursos das famílias, e essa tendência acentua-se quando esses estudos decorrem nos cursos e nas universidades de maior prestígio académico e no mercado de trabalho (Bourdieu e Passeron, 1964; Almeida et al., 1988).

Os poucos estudos extensivos em Portugal sobre a correlação entre o insucesso e o meio social de origem (Sebastião, 2009) ${ }^{3}$ e estudos realizados junto de estudantes universitários mostram que a probabilidade de um aluno oriundo de uma família de operários industriais chegar à universidade é 6 vezes menor do que a de um aluno proveniente de uma família de profissionais técnicos e de enquadramento, 5 vezes menor do que a de um com origem em empresários, dirigentes e profissionais liberais e 4 vezes menor do que a de um descendente de trabalhadores independentes. A posse de capital cultural actua como um filtro ainda mais poderoso: é de 1 para 20 a diferença de probabilidades de frequência de um curso superior por parte de um aluno cujos pais têm no máximo até ao primeiro ciclo do ensino básico e um outro cujos pais possuam um curso superior (Almeida et al., 2003).

13 Na ausência de estatísticas directas, se tomarmos o benefício da acção social escolar como indicador de desfavorecimento, a relação volta a evidenciar-se. É muito significativa a diferença que existe entre o ensino básico e o ensino secundário no que diz respeito à acção social escolar. No primeiro ciclo, no ano de 2008/09, pode-se estimar $^{4}$ que eram abrangidos pelos três escalões da acção social escolar 
aproximadamente $42,5 \%$ dos alunos. No segundo ciclo, o valor sobe para perto de $48,2 \%$. No terceiro ciclo o valor desce ligeiramente para $45,0 \%$. No secundário dá-se uma diminuição para $37,6 \%$. Isto é, a quebra de alunos beneficiários da acção social escolar entre o básico e o secundário é de 7 pontos percentuais.

Neste nível de ensino, em 2005/06 (o último para o qual existem dados), apenas uma proporção muito pequena de alunos beneficiários da acção social escolar chegaram aos exames nacionais nas disciplinas de Português A, Português B e Matemática: respectivamente $4,3 \%, 3,4 \%$, e $2,9 \%$.

Pode-se concluir que a transição para o ensino secundário é afectada pelas condições socioeconómicas das famílias, de um modo que se torna mais intenso quando se olha para os alunos que atingem os exames do secundário.

A estas evidências poderíamos acrescentar os trabalhos de carácter mais microsociológico, como os de Ana Benavente (Benavente, 1988; Benavente et al., 1987; 1994; Abrantes, 2003), ou incidindo sobre grupos específicos como os imigrantes (Machado, 2002; Seabra, 2009). Todos mostram que a relação existe e continua a ser a principal questão em torno da escola e do seu papel social.

\section{Breve balanço das teorias sobre a relação entre origem social e insucesso escolar}

17 A exclusão escolar, traduzida no abandono escolar precoce ou, se assim quisermos chamar, no insucesso escolar, foi revelando que a escola funcionava de modo inadequado à sua missão. Revelação tanto mais problemática quanto mais o capital cultural que a escola deveria assegurar a todos se torna relevante na sociedade e no mercado (Carneiro, 1988; Carneiro (coord.), 2000).

18 A descoincidência entre a missão formal e o desempenho real da escola constitui, por isso, um dos problemas que há mais tempo preocupa as ciências sociais. Problema em parte criado pela própria escola, dada a promessa não cumprida de equidade e justiça social. Mas criado também pela tónica colocada pelas restantes instituições, desde o mercado de emprego às instituições da democracia e da participação cívica, na insuficiência do desempenho das escolas.

19 A questão central é a de saber como se explica a regularidade da relação entre meio social de origem e o trajecto escolar.

20 É muito vasta a literatura sobre o tema ${ }^{5}$. Ela reflecte diferentes visões da escola e do seu papel, além de diferentes avaliações sobre o modo como o desempenha. A abordagem às causas do insucesso escolar comporta enfoques que permitem ter em conta quer os alunos individualmente considerados e as suas famílias, quer as comunidades a que pertencem e as estratégias de actores colectivos como as empresas, as autarquias ou as associações; envolvem as instituições de ensino e formação e os organismos que as enquadram; passam pelos contextos mais vastos da economia, da sociedade e da cultura.

21 Não é possível, por isso, compreender o fenómeno a partir de um modelo explicativo simples, embora seja esse o procedimento mais comum. É, porém, mais enriquecedora a 
consideração de diferentes abordagens, em boa parte complementares. São três as principais abordagens que aqui referiremos:

1. Uma centrada no desajustamento entre a linguagem tradicional da escola e o capital cultural das famílias e dos alunos;

2. Outra centrada nos factores "internos" e específicos do funcionamento do sistema de educação-formação.

3. Uma terceira focada na articulação entre os alunos e as suas famílias, a escola e o mercado de trabalho.

\section{Teorias da dominação cultural} igualdade de oportunidades, reproduz a desigualdade de condições de classe das famílias dos alunos, conhecida como teoria do handicap ou da dominação cultural, foi proposta por Bourdieu e Passeron (s/d). geralmente entre as famílias mais escolarizadas, as crianças são imperceptivelmente preparadas para lidar com o pensamento abstracto (o mesmo que a escola utiliza e requer), ao passo que nas famílias de meios populares prevalecem formas de pensamento, de inteligência e de saber mais marcadas pela experiência prática e pela utilidade instrumental. Os alunos oriundos das famílias menos escolarizadas e culturalmente dominadas são assim colocados em desvantagem perante um discurso de que não se conseguem apropriar.

Resumidamente, esta teoria sustenta a tese de que a escola selecciona os alunos, principalmente, a partir do "capital cultural" das famílias de origem. O mecanismo actua, a maior parte das vezes, de modo imperceptível e tende a ser legitimado pela assumpção, por parte dos alunos e das suas famílias, de que a responsabilidade é sua e da sua "falta de inteligência".

O que acontece, porém, é que a escola "transmite" saberes do mesmo tipo, formais, de modo idêntico, a todos os alunos que a frequentam, sem contudo fornecer as chaves de decifração das linguagens e dos códigos em que esses saberes são transmitidos. Isto é, a escola tende a transmitir saberes mas não fornece os "meta-saberes", ou os requisitos, da respectiva apropriação.

Ora, os códigos culturais das famílias são diferenciados. Por exemplo, nuns casos, Bernard Lahire (2003), mais recentemente, especifica o modo de operação das clivagens operadas na escola, sublinhando a importância da relação dos alunos com a escrita e o seu uso quotidiano, bem como da aquisição de métodos de organização e ordenação das estruturas cognitivas que distinguem os alunos oriundos de diferentes meios sociais ${ }^{6}$.

Note-se que o handicap cultural actua apenas quando a escola funciona de modo tradicional, transmitindo de forma idêntica a todos os alunos saberes para cuja apropriação alguns possuem as ferramentas e outros não. Aquilo que às vezes parece uma decisão de cada aluno, ou o resultado de capacidades "inatas", não é senão o produto das condições que são proporcionadas a cada um, incluindo a informação e a capacidade de discernir vantagens e desvantagens de prosseguir na escola, identificar perigos e oportunidades e ser apoiado nas opções e nos processos de aprendizagem.

Basil Bernstein $(1964 ; 1990)$ propôs uma abordagem semelhante para explicar o insucesso dos alunos de meios populares, ao atribuí-lo a diferenças culturais captáveis 
nos códigos linguísticos utilizados na escola e nas famílias. Há regras e códigos de linguagem estreitamente relacionados com a posição ocupada na divisão social do trabalho. Ora, a cultura escolar é a cultura do poder e os seus códigos linguísticos são os das classes dominantes. Na escola gera-se, assim, incomunicabilidade entre os significados abstractos e generalistas da cultura dominante e a orientação para o "contexto restrito" da cultura de origem dos jovens mais desfavorecidos, determinando negativamente o seu percurso escolar.

Bowles e Gintis (1976) chegam a conclusões muito semelhantes a partir da análise de um contexto nacional distinto dos autores anteriores. $O$ insucesso não se deve nem às características naturais ou naturalizadas dos indivíduos, nem às políticas educativas, mas sim às "relações sociais de escolarização" e à socialização familiar, marcadas por homologias fortes entre o funcionamento da escola e do mundo do trabalho, de que são exemplos a ideologia do mérito na atribuição das recompensas ou as relações de autoridade num e noutro contexto. Deste modo a escola não tem como principal missão transmitir saberes, mas preparar cada um para o seu destino no mercado de trabalho.

Segundo estas (e outras) ${ }^{7}$ teorias, as famílias não são capazes de transmitir a não ser as competências e os capitais que possuem. Ao utilizar um discurso socialmente determinado, a escola reproduz escolarmente as desigualdades sociais, privilegiando os alunos de meios sociais próximos da sua cultura.

O principal problema destas teorias é a pouca utilidade para corrigir os problemas que com razão denunciam. Além disso, não dão resposta ao facto estatisticamente minoritário mas ainda assim relevante do sucesso alcançado por muitas famílias de meios populares que realizam esforços consideráveis para superar o handicap, proporcionando percursos escolares prolongados à descendência. Esse facto, por um lado, confirma a crença de que a escola trata todos de forma igual e, por outro lado, permite realmente que um volume significativo de alunos originários das classes populares obtenha diplomas escolares médios e superiores.

\section{Funcionamento do sistema e dos seus agentes}

O resultado positivo do esforço realizado por alguns jovens de famílias com menores recursos pode ser compreendido à luz de abordagens como as de Boudon (1973, 2001), que rejeitam o determinismo da origem de classe. Para este autor as famílias fazem escolhas racionais e os fenómenos sociais relevantes, como a desigualdade escolar, resultam de mecanismos de agregação das escolhas individuais. A procura agregada de diplomas escolares como via de mobilidade social gera o efeito de massificação do ensino. Paradoxalmente, daí resulta a desvalorização relativa dos diplomas e o aumento do valor daqueles que representam uma efectiva mais-valia no mercado. O investimento necessário para trajectos escolares que dão acesso a esses diplomas faz que os indivíduos calculem racionalmente o que julgam ser a probabilidade de tornar bem-sucedido esse investimento, optando muitos por desistir e outros por prosseguir.

As escolhas dos indivíduos dão-se no quadro de sistemas de interaç̧ão que as condicionam e orientam. Por exemplo, as vantagens ou desvantagens da posse de diplomas escolares afectam o investimento das famílias na escola. As desigualdades escolares resultam assim da avaliação realizada pelas famílias e pelos jovens das 
probabilidades de obter vantagens de uma determinada escolha oferecida pelo sistema escolar.

A condição de classe, a etnicidade, o território ou até o género condicionam a avaliação. Porém não actuam autonomamente, mas com a mediação do sistema de interaç̧ão escolar. É relevante a este respeito o papel desempenhado pelas expectativas que os professores alimentam a respeito do potencial dos seus alunos, que se projecta no modo como os abordam, acompanham, avaliam e organizam em/nas turmas. Se as expectativas são baixas, mesmo que sem discriminação activa, elas acabam por se repercutir na atitude das crianças e das famílias (Van Zanten, 1996). O modo como o sistema escolar opera conta.

Nesta perspectiva, muito do que o aluno é resulta do que a escola faz com ele. O contexto escolar assume, por isso, um papel determinante. Salientamos aqui alguns aspectos determinantes, como:

-A frequência do ensino pré-escolar (Conselho Nacional de Educação, 2009);

- A qualidade da aquisição de competências básicas (Lucília Salgado et al., 2010), nomeadamente no domínio da leitura, da escrita e da fala da língua materna e da matemática, nos primeiros anos de escolaridade;

- 0 domínio das TIC como ferramenta de acesso à informação fundamental (Gonçalves, 2006);

- A construção do currículo e os equilíbrios que comporta entre aprendizagens básicas, aprendizagens específicas nas diferentes áreas do saber (conteúdos disciplinares), e aprendizagens instrumentais (competências); o modo como se integram saberes geralmente dispersos pelas diversas disciplinas; a coerência e articulação entre ciclos e a permeabilidade entre vias (Pacheco (org.), 2000; Goodson, 2001; Gomes, 2002; Pacheco, 2005; Ávila, 2008);

- A detecção e a actuação precoce sobre o risco de retenção e abandono (Grahay, 1996);

- A organização do processo educativo, desde o funcionamento geral da escola e das suas múltiplas instâncias, até à sala de aula (Barroso (org.) 1996);

- A ausência de elementos de identificação positiva dos alunos com a escola (Canavarro et al., 2004);

- O projecto de escola e a diversificação da oferta educativa (Roldão e Marques, 2000);

- A existência e nível de desempenho de serviços de orientação e apoio (Cedefop, 2008);

- A qualidade dos equipamentos, das instalações, das condições materiais de trabalho e dos acessos às escolas ${ }^{8}$;

- 0 envolvimento dos pais e da comunidade na escola e a existência de medidas de apoio às famílias (Conselho Nacional de Educação, 2004);

- A existência e o grau de eficácia de medidas destinadas a grupos de alunos com particulares dificuldades de aprendizagem e expostos a riscos de ordem diversa, quer associados a factores socioculturais e comportamentais, quer à deficiência, quer ainda à concentração e consequente reforço da pobreza e da exclusão social em meios territoriais problemáticos (Pereira, 2004).

A questão que se coloca à acção visando este conjunto de factores é a de saber quais são os seus limites, num duplo sentido: o da aplicabilidade, dado implicar não apenas recursos, mas também profundas transformações de estruturas institucionais e mentais e a ruptura com dinâmicas duráveis e interesses instalados; o da efectiva capacidade para afectar as escolhas das famílias e dos jovens. 


\section{Relação entre emprego, escola e estratégias familiares/pessoais}

Abordagens cujo horizonte é delimitado pela especificidade da realidade portuguesa e com um carácter menos abstracto e genérico do que as teorias referidas anteriormente têm sido desenvolvidas por autores como João Ferrão e Oliveira das Neves (1991), Maria das Dores Guerreiro (2009) ou Luís Capucha (2005).

Todos salientam que a escola, o mercado de trabalho e as famílias formam um triângulo de reforço mútuo que em certas circunstâncias apela para o abandono escolar precoce. As empresas com uma estratégia conservadora de sobrevivência com base na força de trabalho intensiva e pouco qualificada - existentes em todos os sectores de actividade e com todas as dimensões - absorviam com relativa facilidade jovens com baixas qualificações, funcionando como "atracção" alternativa a percursos formativos mais prolongados e qualificantes.

9 Sendo a escola uma instituição orientada primordialmente para a selecção dos alunos que pretendiam e se preparavam para prosseguir estudos (facto que se revela em plenitude na oferta de nível secundário), gerava-se a percepção, de resto com fundamento estatístico, de que eram efectivamente muito limitadas as possibilidades de prosseguir estudos de nível superior, não se justificando a frequência de cursos científico-humanísticos de nível secundário que pouco acrescentavam às condições de acesso ao mercado de trabalho.

O cálculo das famílias e dos jovens relativamente à ausência de ganhos efectivos com uma escolarização mais prolongada empurrava-os para a aceitação de postos de trabalho de baixa qualidade que lhes eram oferecidos a troco de algum aumento dos parcos orçamentos familiares. Isto mesmo é confirmado pelos dados do Inquérito à Educação de Jovens e Adultos do GEPE (2007), segundo os quais duas das três causas mais citadas pelos inquiridos com grau de escolaridade igual ou inferior ao ensino básico para não continuarem a estudar são "querer ganhar o seu próprio dinheiro" (assinalada por $29,0 \%$ dos inquiridos) e "ter dificuldades económicas" (referida por $22,0 \%)$.

Estas estratégias inconscientemente concertadas de grande parte do tecido produtivo, da escola e das famílias de menores recursos baseavam-se em dados objectivos escassez dos orçamentos familiares, oferta de emprego sem qualidade e escola selectiva - e na crença de que a escola não podia mudar a sua orientação no sentido de substituir a selectividade pela inclusão. Parte desta crença vinha acompanhada do desconhecimento do valor efectivo dos diplomas escolares, quando calculado a médio e longo prazo e não apenas à saída da escola. Pesava ainda a ideia de que quem estudava não era para ser um trabalhador, mas sim para obter um estatuto socioprofissional, ao passo que quem tinha como futuro ser um trabalhador não precisaria de estudar. Tratase de uma extensão no ideário popular da oposição entre saber e fazer cultivada pela escola e pelas elites intelectuais e científicas.

Este tipo de representação da realidade foi gerado num contexto que é seguramente já passado, pois hoje estuda-se para ter acesso a uma profissão, e o exercício profissional, qualquer que seja o seu perfil, carece de aprendizagem permanente ao longo e em todos os contextos da vida. 
43 A oposição entre saber e fazer tem uma forma especificamente escolar, com grande lastro histórico: a hierarquização e segmentação/impermeabilidade das vias de ensinoaprendizagem, que valoriza os cursos para o prosseguimento de estudos e desvaloriza as vias vocacionais 9 . De facto, um dos traços mais marcantes do sistema era a tradicional subalternidade das vias vocacionais no ensino, em particular no secundário, estabelecendo-se as vias de prosseguimento de estudos como a acepção socialmente sancionada do conhecimento, sendo o prosseguimento imediato de estudos o trajecto “normal" de escolarização para quem entrava no secundário.

São dois os problemas principais resultantes actualmente do cruzamento das lógicas da escola selectiva, das famílias que julgam ser escasso o retorno provável do investimento escolar e das empresas intensivas em trabalho pouco qualificado. Por um lado, vive-se actualmente uma dinâmica estrutural que leva ao crescimento dos empregos de qualificações médias e superiores e à rápida destruição dos empregos menos qualificados. Não há qualidade de vida no presente e no futuro sem qualificações. Por outro lado, à educação é cada vez mais exigido que deixe de ser apenas a instituição a partir da qual se distribuem os jovens pelos seus destinos de classe e pelos correspondentes lugares no mercado de trabalho, para desempenhar um papel de preparação de cidadãos e profissionais capazes de lidar com as oportunidades e os riscos da economia do conhecimento e da sociedade de informação. Isto é, os cidadãos têm direito à educação e à formação de excelência, mas também com equidade (Conselho Europeu, 2010).

Em síntese, a abordagem da interacção sistémica entre o mercado de trabalho e as classes sociais que dele emergem, as atitudes e práticas das famílias, organizadas segundo uma racionalidade marcada tanto pela apreciação de oportunidades efectivas como por falsas representações da realidade, e o modo como a escola e os seus profissionais funcionam, incluindo o modo como se relacionam com as empresas e com alunos de diferentes meios sociais, implica a mobilização tanto das teorias da dominação cultural como das teorias da escolha racional dos agentes para a compreensão do insucesso escolar e para vislumbrar a possibilidade de combater o fenómeno.

\section{Capacidades e oportunidades: o que podem fazer as qualificações?}

Confrontam-se hoje em dia no campo da educação duas correntes de opinião, uma que valoriza essencialmente a instrumentalidade da educação face à economia, ao serviço da qual alguns crêem que ela deveria estar (é a posição que sobressai em muitos documentos da OCDE, por exemplo), e outra que valoriza a educação em si mesma, independentemente da sua utilidade económica (Canário, 2000; Lima, 2006). Trata-se, na verdade, de duas formas de distorcer aquilo que se julga ser a perspectiva educativa mais responsável, chamando-se a atenção para a totalidade do ser humano e para o papel da educação na realização pessoal, social e económica dos cidadãos, bem como para o contexto em que essa realização se joga.

Esse papel vai, na verdade, para além do aumento da produtividade, da competitividade e da empregabilidade, afectando as estruturas profundas da sociedade. De facto, apesar de tudo, a escola é praticamente o único grande factor de mobilidade social disponível 
nas sociedades modernas (Cabral, 2008; Almeida et al., 2003). E sê-lo-á tanto mais quanto menos recursos possuírem as famílias para deixar como herança aos seus filhos (assumam esses recursos a forma de capital económico, social ou cultural). Assim, ela é essencial para o combate à pobreza e, em particular, à sua reprodução intergeracional.

Amartya Sen (1999) inscreveu nos debates sobre a pobreza a nível internacional ${ }^{10}$ a ideia de que ela se liga, por um lado, às oportunidades resultantes do modo como funcionam, com maior ou menor abertura, sistemas de referência como o mercado de trabalho, a segurança social, a acção social e as próprias instituições da democracia e, por outro lado, às capacidades incorporadas nas pessoas. A sobreposição dos dois elementos determina o grau e o sentido de mobilidade, a igualdade de oportunidades e o nível das desigualdades existente em cada sociedade.

Ora, a qualificação das pessoas e a respectiva certificação são um factor-chave do ponto de vista das capacidades e do seu reconhecimento público. As duas questões que se colocam a este propósito são: como é que podem ser promovidas? Que oportunidades existem para lhes aceder?

50 A hipótese que se avança é a de que apenas operando a mudança do que tem vindo a ser conhecido como o paradigma do ensino para o paradigma das competências (UNESCO, 1985) se conseguirá a democratização do acesso às qualificações e a generalização do sucesso aos diplomas que as atestam.

51 A mudança implica romper com a ideia de que apenas existe uma via legítima para aprender, assente na transmissão unidireccional de conteúdos e saberes disciplinares a alunos que os aproveitam, como se diz na linguagem escolar corrente. 0 aproveitamento, e consequente selecção, é aferido pelos segmentos educativos frequentados (que cursos se tiram, em que escolas, durante quanto tempo) e por exames que tendem a reter toda a concentração dos alunos, os quais rapidamente esquecem o que tiveram de decorar para obter uma determinada nota. Ora, o que realmente importa é valorizar competências não apenas no plano do saber, mas também do saber fazer e do saber aprender. A Recomendação do Parlamento Europeu e do Conselho de 23 de Abril 2008 sobre o estabelecimento do Quadro Europeu de Qualificações para a aprendizagem ao longo da vida (2010) expressa esta posição ao encorajar uma mudança da ênfase tradicional nos "inputs de aprendizagem" para uma aproximação baseada nos "resultados da aprendizagem", isto é, o que o aprendente sabe, compreende e é capaz de fazer. Neste quadro, importa menos onde e como se aprendeu do que a utilização que se é capaz de dar ao conhecimento.

No plano pedagógico, as metodologias de ensino colocam não as disciplinas mas o sujeito aprendente no centro do processo e privilegiam a experimentação, a combinação entre as teorias e as práticas, a articulação entre o estudo e a aprendizagem de saberes técnicos e operativos.

Esta abordagem permite aos alunos de meios mais desfavorecidos progredirem escolarmente, como mostra o facto de nos subsistemas em que esses alunos predominam, como o sistema de aprendizagem e os cursos profissionais, o sucesso escolar ser maior do que nos cursos gerais, que apesar da selectividade que comportam apresentam piores resultados. Por serem os primeiros mais "fáceis", argumentarão alguns. Mas responderá quem tiver acompanhado ambas as realidades que a razão do sucesso está nos métodos pedagógicos, na intensidade do trabalho e no acompanhamento muito mais próximo aos alunos, quer nas matérias de pendor mais 
teórico, quer nas disciplinas técnico-profissionais e nas experiências de contacto com o mundo do trabalho.

De resto, a mesma abordagem, com as devidas adaptações organizativas, produz resultados semelhantes também entre a população adulta que, a seu tempo, foi excluída da escola, mas que a ela pode e quer aceder se a oportunidade se lhe oferecer. Isto é, em conclusão, não apenas a mudança de paradigma pode romper o ciclo da pobreza promovendo o sucesso escolar dos jovens, como pode oferecer mais e novas oportunidades àqueles que um dia foram excluídos, mantendo porém o direito à aprendizagem e à sua valorização social, pessoal e profissional. Desideratos básicos no combate à pobreza e à exclusão social.

\section{BIBLIOGRAFIA}

ABRANTES, P. (2003). Os Sentidos da Escola. Identidades juvenis e dinâmicas de escolaridade, Oeiras, Celta Editora.

ALMEIDA, J. F., et al. (1988), "Famílias, estudantes e universidade”, Sociologia. Problemas e Práticas, 4, pp. 11-44.

ALMEIDA, J. F. et al. (2003), Diversidade na Universidade. Um Inquérito aos estudantes de licenciatura, Oeiras, Celta Editora.

ÁVILA, P. (2008), A Literacia dos Adultos. Competências-Chave na Sociedade do Conhecimento, Lisboa, CIES-ISCTE e Celta Editora.

BARROSO, J. (org.) (1996), o Estudo da Escola, Porto, Porto Editora.

BAUDELOT, C. e R. Establet (1971), L'École Capitaliste en France, Paris, Maspéro.

BENAVENTE, A. (1988), "Da Construção do Sucesso Escolar - equacionar a questão e debater estratégias”, Seara Nova, 18, pp. 2-6.

BENAVENTE, A. (1990), “O Insucesso Escolar no Contexto Português - abordagens, concepções e políticas, Análise Social, vol. XXV, 108-109, pp. 715-733.

BENAVENTE, A., et al. (1994), Renunciar à Escola. O abandono escolar no ensino básico. Lisboa, Fim de Século.

BENAVENTE, A., et al. (1987), Do Outro Lado da Escola, Lisboa, Edições Teorema.

BERNSTEIN, B. (1964), "Elaborated and Restricted Codes: their social origins and some consequences", American Anthropologist, 66, pp.55-69.

BERNSTEIN, B. (1990), Poder, Educación y conciencia. Sociología de la transmisión cultural, Barcelona, El Roure Editorial.

BOUDON, R. (1973), L’Inégalité des Chances, Paris, A. Colin.

BOUDON, R. (2001), “Les Causes de l'inégalité des chances scolaires”, in Boudon, Bulle e Cherkaoui, École et Société. Les Paradoxes de la Démocratie, Paris, PUF. 
BOURDIEU, P. (1987), “Propostas para o Ensino do Futuro", Cadernos de Ciências Sociais, 5, pp. 101-119.

BOURDIEU, P. e J.-C. Passeron (1964), Les Héritiers. Les Étudiants et la Culture, Paris, Editions de Minuit.

BOURDIEU, P. e J.-C. Passeron (s/d), A Reprodução. Elementos Para uma Teoria do Sistema de Ensino, Lisboa, Vega.

BOWLES, S. e H. Gintis (1976), Schooling in Capitalist America. Educational reform and the contradictions of economic life, Londres, Routledge \& Kegan Paul.

CABRAL, M. V. (org.) (2008), "Conferência Internacional Sucesso e Insucesso. Escola, Economia e Sociedade”, Lisboa, Fundação Calouste Gulbenkian.

CANÁRIO, R. (2000), Educação de Adultos. Um Campo e uma Problemática, Lisboa, Educa.

CANAVARRO, J., et al. (2004), Eu não Desisto: Plano Nacional de Prevenção do Abandono Escolar, Lisboa, Ministério da Educação e Ministério da Segurança Social e do Trabalho (policopiado).

CAPUCHA, L. (1998), "Exclusão Social e Acesso ao Emprego: paralelas que podem convergir”, Sociedade e Trabalho, 3, pp. 60-69.

CAPUCHA, L. (2005), Desafios da Pobreza, Oeiras, Celta.

CAPUCHA, L., et al. (2009), Mais Escolaridade - Realidade e Ambição. Estudo preparatório do alargamento da escolaridade obrigatória, Lisboa, ANQ, I.P.

CARNEIRO, R. (1988), Educação e Emprego em Portugal: uma Leitura de Modernização, Lisboa, Fundação Calouste Gulbenkian.

CARNEIRO, R. (coord.) (2000), o Futuro da Educação em Portugal. Tendências e Oportunidades. Um Estudo de Reflexão Prospectiva, Lisboa, Ministério da Educação, Departamento de Avaliação, Prospectiva e Planeamento.

CEDEFOP (2008), Establishing and Developing National Lifelong Guidance Policy Forums: a manual for policymakers and stakeholders, Luxemburgo, Panorama Series, 153, Office for Official Publications of the European Communities.

CONSELHO EUROPEU (2010), Council Conclusions of 11 May 2010 on Competences Supporting Lifelong Learning and the "new skills for new jobs" Initiative, Oficial Journal of the European Union, 2010/C 135/03.

CONSELHO NACIONAL DE EDUCAÇÃO (2004), Educação e Família, Lisboa, CNE.

CONSELHO NACIONAL DE EDUCAÇÃo (2009), A Educação das Crianças dos 0 aos 12 Anos, Lisboa, CNE. FERRÃO, J. e A. Oliveira das Neves (1991), Caracterização Regional dos Factores do Abandono Escolar no 2.e 3.․ㅡㄴ Ciclos do Ensino Básico, Lisboa, PEPT.

GEPE (2007), Inquérito à Educação de Jovens e Adultos: Relatório, Lisboa, Gabinete de Estatística e Planeamento da Educação.

GOMES, M. do C. (2002), Literacia e Educação de Adultos: percursos, projectos e efeitos. Um estudo de caso, Lisboa, ICS (tese de mestrado).

GONÇALVES, N. (2006), A Utilização de Ambientes Virtuais em Contexto Educativo. Perspectiva dos Professores do 1.․ㅡㄹ Ciclo do Ensino Básico, Lisboa, Direcção Geral de Inovação e Desenvolvimento Curricular. 
GOODSON, I. (2001), o Currículo em Mudança. Estudos na construção social no currículo, Porto, Porto Editora.

GRAHAY, M. (1996), Podemos lutar contra o Insucesso Escolar?, Lisboa, Instituto Piaget.

GUERREIRO, M. das D. (coord.) (2009), Trajectórias Escolares e Profissionais de Jovens com Baixas Qualificações. Relatório Final, Lisboa, CIES-ISCTE.

LAHIRE, B. (2003), “Crenças Colectivas e Desigualdades Culturais”, Educação e Sociedade, 24 (84), pp. 983-995.

LIMA, L. (2006), Educação Não Escolar de Adultos. Iniciativas de Educação e Formação em Contextos Associativos, Braga, Universidade do Minho.

MACHADO, F. L. (2002), Contrastes e Continuidades. Migração, etnicidade e integração dos guineenses em Portugal, Oeiras, Celta Editora.

OECD (2009a), Innovation Strategy for Education and Training, Progress Report n.․ 2, EDU/CERI/ $\mathrm{CD}(2009) 20$.

OECD (2009b), Learning for Jobs. OECD Policy Review of Vocational Education and Training, Initial Report, Directorate for Education. Education Policy Committee, Centre for Educational Research and Innovation Governing Board.

PACHECO, J. A. (2005), Estudos Curriculares - para a compreensão crítica da educação, Porto, Porto Editora.

PACHECO, J. A. (org.) (2000), Políticas de Integração Curricular, Porto, Porto Editora.

PEREIRA, F. (2004), Políticas e Práticas Educativas - o caso da educação especial e do apoio sócioeducativo nos anos 2002 a 2004, Lisboa, Fundação Liga.

RODRIGUES, M. de L. (2010), A Escola Pública Pode Fazer a Diferença, Coimbra, Almedina.

ROLDÃo, M. do C. e R. Marques (2000), Inovação, Currículo e Formação, Porto, Porto Editora.

SALGADO, Lucília, et al. (2010), CNO: uma Oportunidade Dupla. Da promoção da literacia familiar ao sucesso escolar das crianças, Relatório de Pesquisa, Coimbra, Escola Superior de Educação de Coimbra.

SEABRA, T. (2009), "Desigualdades Escolares e Desigualdades Sociais”, Sociologia. Problemas e Práticas, 59, pp. 75-106.

SEBASTIÃO, J. (2009), Democratização do ensino, desigualdades sociais e trajectórias escolares, Lisboa, Fundação Calouste Gulbenkian e Fundação para a Ciência e a Tecnologia.

SEN, A. (1999), Development as Freedom, Oxford, Oxford University Press.

TERRAIL, J.-P. (2002), De L'Inégalité Scolaire, Paris, La Dispute.

UNESCO (1985), Cuarta Conferencia Internacional sobre la Educación de Adultos, Paris, consultado em 15.11.2010 em www.unesco.org/education/uie/confintea/paris_s.pdf.

VAN ZANTEN, A. (1996), "Fabrication et Effets de la Ségrégation Scolaire”, in S. Paugam (org.), L'Exclusion. L'état des savoirs, Paris, Éd. La Découverte.

\section{NOTAS}

1. Como se sabe, os dados publicados em 2008 pelo Eurostat referem-se aos rendimentos de 2007. Eles indicavam para Portugal uma taxa de risco de pobreza após as transferências sociais de 
$17,9 \%$, o que corresponde à proporção da população cujo rendimento por adulto equivalente é inferior a 喝 414,00 por mês ou 节 $4.969,00$ por ano, sendo este valor $60 \%$ do rendimento mediano em Portugal naquele ano. O facto de não termos disponíveis dados mais recentes releva da circunstância de existir uma lamentável e incompreensível homologia entre o fenómeno medido (a pobreza) e a pobreza das estatísticas que o medem.

2. Dados provisórios para o ano lectivo 2007/2008; dados para Portugal Continental (Público e Privado). Inclui dados relativos a Cursos EFA e Ensino Recorrente. As taxas de escolarização para os diferentes anos foram calculadas tendo como base os dados das estimativas da população residente do INE

3. Como as estatísticas da educação não fornecem esta informação, são particularmente complexos, do ponto de vista metodológico, esses estudos.

4. Tanto os dados dos alunos inscritos como os dados dos beneficiários da acção social escolar são provisórios.

5. Para uma revisão bibliográfica do tema com realce para a produção nacional ver, por exemplo, Benavente et al. (1994). Mais recentemente, João Sebastião (2009) produziu uma importante síntese das teorias do insucesso escolar.

6. Estes dados são consistentes com o que se sabe acerca da relação entre a escolaridade, a aquisição precoce de hábitos de leitura, a literacia emergente na criança e os resultados escolares.

7. Por exemplo, as de Baudelot e Establet (1971).

8. Curiosamente, sendo este um problema dos mais referidos no discurso quotidiano dos agentes educativos e na comunicação social, é dos menos estudados cientificamente.

9. Esta ideologia aparece frequentemente, ainda, na esfera pública, com duas tonalidades apenas aparentemente opostas. Uma, de tipo fundamentalista, considera que apenas os saberes disciplinares abstractos são "verdadeiros" e exigentes. A outra, relativista, afirma que toda a experiência tem o mesmo valor e que, sendo a educação holística (isto é, considerando a pessoa como um todo), todas as competências são igualmente relevantes. Ambas convergem na desvalorização da aquisição de competências úteis para a vida activa, opondo-a ao que seria, quer na perspectiva da tradição "escolástica" quer na da tradição da chamada "educação popular", um desvirtuamento da função do ensino. Ora, a posição que aqui se assume é a de que a educaçãoformação deve assegurar a aquisição por parte de todos de competências-base sólidas, a valorização das pessoas e das suas capacidades como cidadãos inovadores, críticos, capazes de aprender e participar, conhecedores do mundo, capazes de comunicar num mundo plural mas, também, preparados para a vida profissional, a qual continua a ter um papel central na estruturação das sociedades e na configuração do estatuto e das condições de vida dos indivíduos. 10. Em Portugal foi defendida a abordagem aos factores de pobreza em termos de capacidades e oportunidades em 1998 (Capucha, 1998).

\section{RESUMOS}

Há uma relação entre a escolaridade e a desigualdade social. Essa relação é evidenciada, por exemplo, pelos indicadores estatísticos de pobreza. A sociologia da educação vem alertando há muito para a associação entre a origem social, o desempenho escolar e as respectivas consequências nas oportunidades de vida. É possível pôr fim a esta situação? Defende-se no presente artigo que as qualificações são um instrumento poderoso de capacitação das pessoas e, 
por essa via, de promoção da igualdade de oportunidades. Tal depende de mudanças a operar na escola, de forma a valorizar as competências, isto é, os saberes e a sua utilização na vida social, pessoal e profissional, favorecendo dessa forma o acesso ao conhecimento e às qualificações certificadas por parte de jovens e adultos oriundos de meios populares.

There is a relationship between schooling and social inequality. This relationship is evidenced, for example, by statistical indicators of poverty. The sociology of education has long been warning for the connections between social background, school performance and their impact on life chances. Is it possible to put an end to this situation? It is argued in this article that the qualifications are a powerful tool for empowering people and, in this way, the promotion of equal opportunities. This depends on changes to be promoted in school in order to enhance the skills, that is, the knowledge and its use in social, personal and professional contexts, thus promoting access to knowledge and skills certified by young people and adults from popular social backgrounds.

\section{ÍNDICE}

Keywords: qualification, poverty, education, training

Palavras-chave: qualificações, pobreza, educação, formação

\section{AUTOR}

\section{LUÍS CAPUCHA}

Investigador do CIES/ISCTE-IUL luiscapucha@sapo.pt 